\title{
Energy, resource consumption, and climate change
}

\author{
Don $\operatorname{Kerr}^{1}$
}

\begin{abstract}
Population growth, at both the national and global level, will most certainly impact Canada's climate and, more broadly, its environment. While Canada's population has been projected to continue to grow for many decades, what happens elsewhere in terms of population growth will be particularly important to Canada. Although Canada's greenhouse gas (GHG) emissions have levelled off somewhat over the last decade and a half, global emissions have continued to climb. As a direct result, with increased GHG emissions in the atmosphere, Canada's northern climate has already been impacted in a major way, with considerable warming, particularly in its most northern forests and Arctic ecosystems.
\end{abstract}

Keywords: population and environment; climate; energy use; peak population; greenhouse gas emissions

\section{Résumé}

L'accroissement de la population, autant à l'échelle nationale que mondiale, aura certainement un effet sur le climat au Canada et, plus largement, sur son environnement. Selon les projections, la population canadienne devrait continuer à augmenter pendant encore plusieurs décennies. Or, ce qui se passe ailleurs en termes d'accroissement de la population sera particulièrement important pour le Canada. Bien que les émissions de gaz à effet de serre (GES) au Canada se soient nivelées au cours de la dernière décennie et demie, les émissions globales ont cependant continué à grimper. En conséquence directe de cette augmentation de GES dans l'atmosphère, le climat dans le nord du Canada a déjà subi un impact majeur par un réchauffement important, surtout dans les forêts les plus au nord et les écosystèmes arctiques.

Mots-clés : population et environnement; climat; utilisation d'énergie; pointe de population

\section{Introduction}

There are important potential effects of global peak population on Canada's economy, as well as on forecasted levels of resource production and consumption. Yet this population growth, at both the national and global level, will also impact Canada's climate and, more broadly, its environment. While Canada's population has been projected to continue to grow for many decades, as impacted by future immigration targets, what happens elsewhere in terms of population growth and economic development will be particularly important. Although Canada's greenhouse gas (GHG) emissions have levelled off somewhat over recent years (with a very slight decline since 2005), global emissions have continued to climb rapidly — up by about 20 per cent over the 2005-16 period (Environment and Climate Change Canada 2017a). As a direct result, with increased GHG emissions in the atmosphere, Canada's northern climate has already been impacted, with considerable warming, particularly in its most northern forests and Arctic ecosystems (Thomson et al. 2017; Pizzolato et al. 2013).

1. King's College DL 312, 266 Epworth Ave., Western University, London, ON N6A 2M3; email: dkerr@uwo.ca. 


\section{Emerging issues: World population and Canada}

Canada and many industrialized countries face the prospect of slower growth and population aging, whereas other world regions continue to face major challenges associated with rapid population growth. All countries, however, face environmental effects resulting from population change. The United Nation's medium-growth projection (UN 2017) suggests that the world's population could add an additional 2.3 billion over the 2015-50 period before leveling off somewhat (this is not an inconsequential increase, because it is close to the combined current population total for China and India). While the global population growth rate is currently about 1.1 per cent, the UN medium-growth scenario suggests a growth rate of about 0.4 per cent by 2050 . Even with the low variant, which assumes a major drop in fertility to levels below replacement, the population momentum inherent in the world's current age structure insures an additional 1.3 billion over the next half-century.

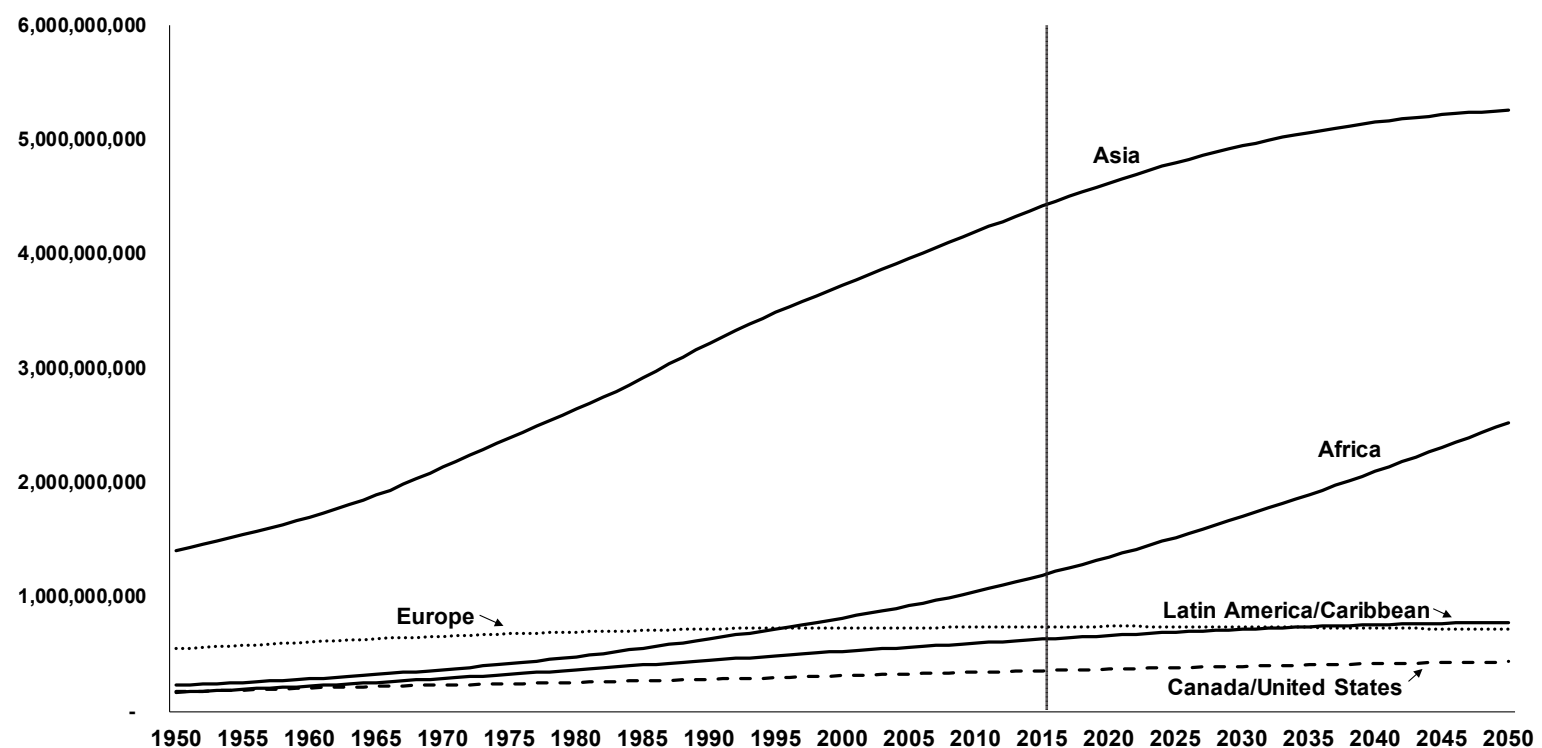

Figure 1. Global population growth, United Nations medium variant, 2017.

Source: United Nations 2017.

While UN projections suggest that North America (Canada and the United States) should maintain its share of the global population (roughly 5 per cent), some world regions are expected to increase dramatically. For example, Africa's share of the global population is set to rise from 16 per cent currently to about 26 per cent by mid-century, with a projected growth of 1.4 billion. Asia's growth is expected to involve an additional 800 million, whereas the Americas could easily see an additional 200 million by mid-century. This sort of population growth, in and of itself, is likely to increase the demand for Canadian exports and resources. This is particularly true given the importance of the resource sector to Canada's economy, as well as ongoing efforts to extend our traditional trading relationships beyond the United States and Mexico to other parts of the world, including Europe and other parts of the Americas, as well as to expanding markets situated across the Pacific Rim. 


\section{Canada's environmental record}

By international standards, Canada's environmental record has been mixed. As an indication of this, the Yale Centre for Environmental Law and Policy recently published a ranking of 180 countries according to a composite index meant to measure "sustainable development." While the reference measure is somewhat vague, it essentially refers to "maintaining or improving the economic and social welfare of societies without doing irreparable damage to the environment." The composite index summarizes data across 20 public health and environmental indicators. Although Canada's record has been superior in terms of "promoting the social welfare of its population," it has been judged problematic in terms of "avoiding irreparable damage to the environment." Canada scored 25th overall, yet its relative ranking could have been much higher had it not been for its relatively poor performance on several of the indicators meant to measure "environmental damage." As an example, Canada currently ranks 107th in terms of the indicator of "CO 2 emissions per KWH" (Hsu et al. 2016).

This is consistent with what has been documented elsewhere; for example, the World Resources Institute (2016) has shown that Canada currently ranks 11th-highest internationally in terms of GHG emissions on a per capita basis. Environment and Climate Change Canada (2017b) has recently published estimates and forecasts on GHG emissions (Figure 2), which demonstrate the extent to which Canada has failed to meet past commitments on greenhouse emissions (incl. Kyoto and Copenhagen) and is likely to miss future international commitments (Paris). Based on historical data and a review of all actions taken by the government through to November 2016, Environment and Climate Change Canada has forecasted that Canada is set to miss its current international commitment at Paris of 520 megatons of $\mathrm{CO}_{2}$ equivalent by 2030 (projected emissions range between 697 and 790 megatons under current policy/proposed regulations). While Canada has reduced its total emissions by about 2 per cent over the 2005-15 period, future emissions must be reduced by an additional 28 per cent by 2030 in order to reach its Paris commitments.

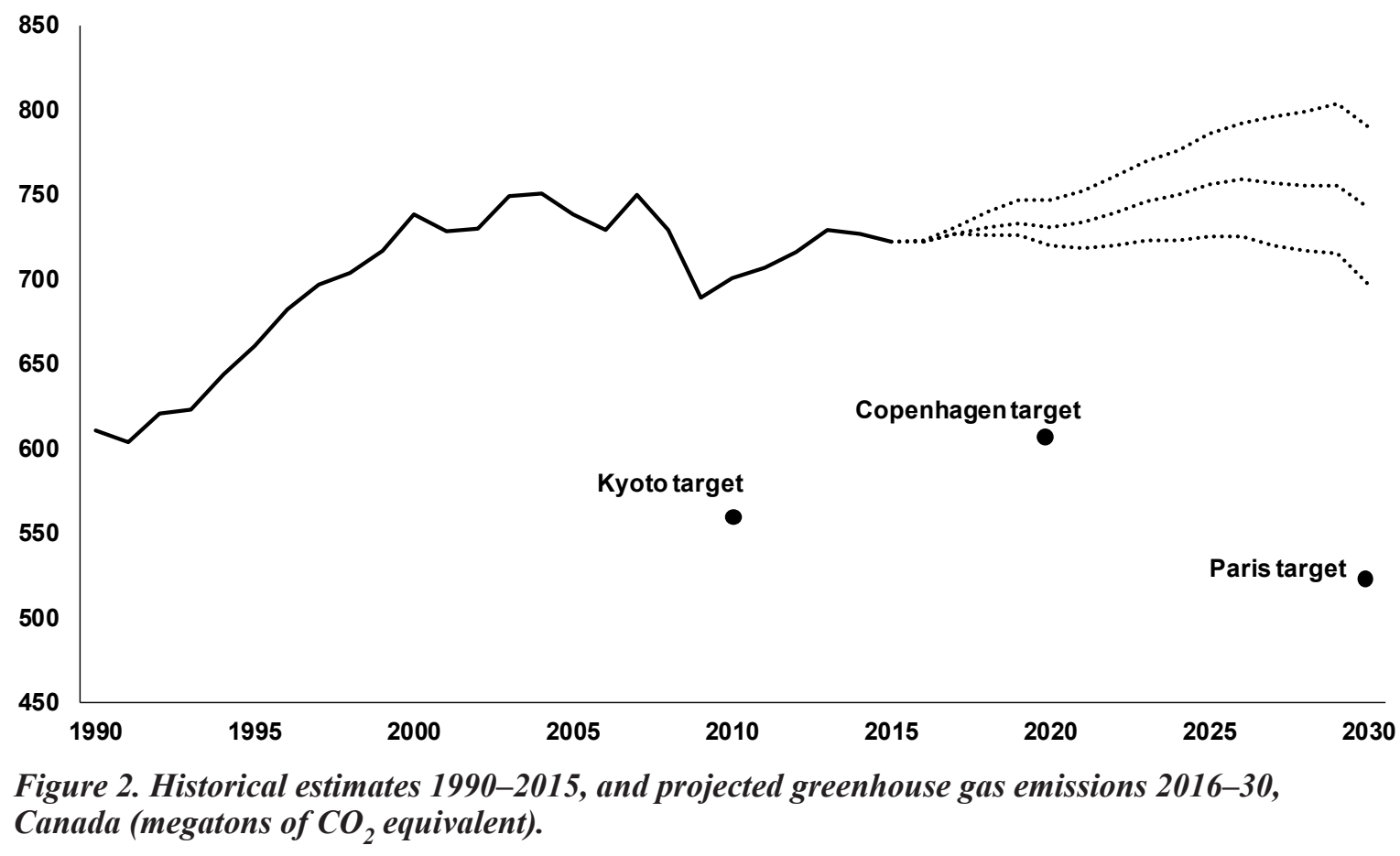

Source: Environment and Climate Change Canada 2017b. 
There is considerable uncertainty in these projections. For example, it is impossible to predict with any precision future growth in demand for Canadian commodities (including energy), just as it is impossible to predict future initiatives or regulations introduced by all levels of government. Yet in an independent set of forecasts, the International Energy Association has predicted that on a "global level", the demand for oil should continue to grow until at least 2040 (IEA 2017). This is largely due to the lack of easy alternatives to oil in the petrochemical, road freight, and aviation industries. In this context, it is reasonable to anticipate a growing demand for Canadian exports, and in particular a demand for Canada's energy resources.

\section{The Environmental Kuznets Curve}

A relevant idea in this context is the "environmental Kuznets curve," i.e., the general idea that relatively poor societies do little to protect their environment and that only with economic development can societies better afford the costs of protecting the environment, enforcing standards for a cleaner environment and actually cleaning up pollution from the past (Kuznets 1955). The general idea here is that at earlier stages of economic development, economic activity leads to major deterioration in the environment. The purported is that this situation can shift as a society becomes wealthier and its economy diversifies. The general idea is that once a society reaches a given level of development, the nature of economic activity can shift in a major way (for example, away from the primary sector and/or manufacturing to services and a post-industrial economy) and that such a society can better afford to improve its relationship with the environment.

Saunders (2017a) has recently argued that Canada is already moving through this transition, a situation that he foresees continuing even in the context of major demographic growth and climbing living standards. For example, Saunders points to a few fundamental trends, i.e., what has been happening in terms of the energy intensity (and energy efficiency) of economic activity in Canada, as well as the carbon intensity of our economy. As he points out, on these indicators we have seen gains; for example, Canada (and Ontario in particular) has reduced the amount of coal that enters into its energy mix, just as Alberta and Saskatchewan have set out to regulate GHG emissions from the oil sands. Yet regardless, as demonstrated in Figure 2, GHG emissions have essentially not declined, nor are they expected to decline anytime in the near future.

While the energy and carbon intensity of economic activity has improved, this has been offset by both demographic and economic growth. And on a global level, emissions have been climbing in a major way, specifically in those nations that have yet to move through any such transition. Large segments of the world's population continue to face significant challenges in terms of meeting even the most basic energy needs.

\section{Reasons for both optimism and pessimism}

By the criteria of the Environmental Kuznets Curve, Canada has a better record than most on several of the indicators summarized by the Yale Centre for Environmental Law and Policy (e.g., providing clean drinking water, assuring appropriate wastewater treatment, maintaining air quality, and reducing fine airborne particulate matter in its metropolitan areas). Yet on several other indicators of environmental vitality, Canada continues to rank relatively poorly (e.g., $\mathrm{CO}_{2}$ emissions, biodiversity and habitat loss, fish stocks, change in forest cover, species protection). In many ways, Canada's environment continues to deteriorate, even with the best of intentions for environmental protection and regulation. As merely an example, consider the unintentional introduction of in- 
vasive species into Canadians waterways, including the Great Lakes region, which has had a negative impact in terms of biodiversity (Environment Canada and the US Environmental Protection Agency 2014; Mandrak and Cudmore 2010). And again, while Canada's record on protecting the environment is mixed, what happens elsewhere is of fundamental importance to Canada. We return here to the basic observation that GHG emissions globally are up by 20 per cent in 2005-15, while Canadian emissions require an additional 28 per cent reduction by 2030 in order to reach its Paris commitments.

In a related matter, the Yale Center reports that Canada was among the top three countries in 2014 in terms of annual tree cover loss (behind only Russia and Brazil), despite some of the best efforts introduced over recent years on the part of the forestry industry to introduce more sustainable practice (Hsu 2016). In particular, this sector can be credited for the application of science-based approaches to the management of forest resources, and considerable effort invested in reforestation. Yet despite such efforts, the health and biodiversity of Canadian forests have declined. While forestry, timber, and other commercial activities have been implicated in tree cover loss, far more important has been the impact of climate change: fires and insect infestations have worsened in extent and intensity as the climate in northern latitudes has warmed, with drier conditions (Aitken 2015). British Columbia in particular has witnessed a major infestation of the mountain pine beetle at latitudes previously unheard of, which is linked to milder winters and earlier arrival of spring. In a subtle and more gradual manner, both the flora and fauna composition of Canada's forests and tundra regions have been impacted, as degraded ecosystems impact biodiversity. The health of Canadian forests has in turn impacted Canada's ranking on other indicators; for example, Canada could potentially do much better on minimizing biodiversity loss and habitat protection.

\section{Canada's warming climate}

Over the last 69 years of careful record-keeping across Canada, Environment and Climate Change Canada (2017c) has captured a linear trend for the country as a whole that indicates a warming of about 1.5 degrees Celsius during the summer months and fully 3.3 degrees Celsius during the winter months (Figure 3). In working with annual averages rather than the aforementioned seasonal changes, Canada has warmed at a rate that is about twice the global average (Environment Canada 2015). While Canada produces more than its share of GHG emissions, so too has it witnessed greater warming of its climate - an inference which is true across several high-latitude regions, including Alaska, Greenland, Siberia, and other regions of northern Europe and Asia. This has led to many profound changes in the north, including the melting of glaciers and sea ice, softening of much of the northern tundra, and a real impact upon the health of the boreal forest.

In contrast, the most southern and densely populated regions of the country have witnessed much less warming, particularly during the summer months, regardless of public perceptions. Over the next several decades, the International Panel on Climate Change (IPCC) forecasts that this warming will be felt increasingly in the more southern regions of Canada, with uncertain environmental and social effects (Romero-Lankao et al. 2014). Whereas Environment and Climate Change Canada has recently documented that 2016 was its fourth-warmest year on record (2010 was the warmest), temperatures were not far from average throughout much of southern Canada. While in 2016 the national average was 2.1 degrees Celsius above Environment Canada's baseline average, temperatures were of the range of 3 to 4 degrees above this same baseline 
throughout much of Nunavut and the eastern Arctic. In terms of winter temperatures, Yukon had its warmest winter on record (fully 6.8 degrees above average), with comparable anomalies in the Northwest Territories and the northernmost forests of Alberta, Saskatchewan, and Manitoba (5.1 degrees).

To provide a broader context, NASA (2017) has reported that the global average was 0.99 degrees Celsius warmer than the 20th-century mean, making 2016 the third year in a row to set a new record for average surface temperatures. The impact of this warming, particularly in the far north, is of growing concern to climate scientists in light of the potential for climate change feedback loops. The softening of the northern tundra is already having an impact on many northern settlements, whereas the melting of sea ice is freeing large expanses of the Arctic Ocean to open water. This is leading scientists to worry about the potential release of methane into the atmosphere due to the thawing of the tundra and the absorption of additional heat into the ocean and land surface due to receding ice cover. The concern is that these feedback loops hold the potential for an acceleration in the pace of global warming, as implied in the climate models of some of the IPCC's most pessimistic forecasts (Cubasch et al. 2013).

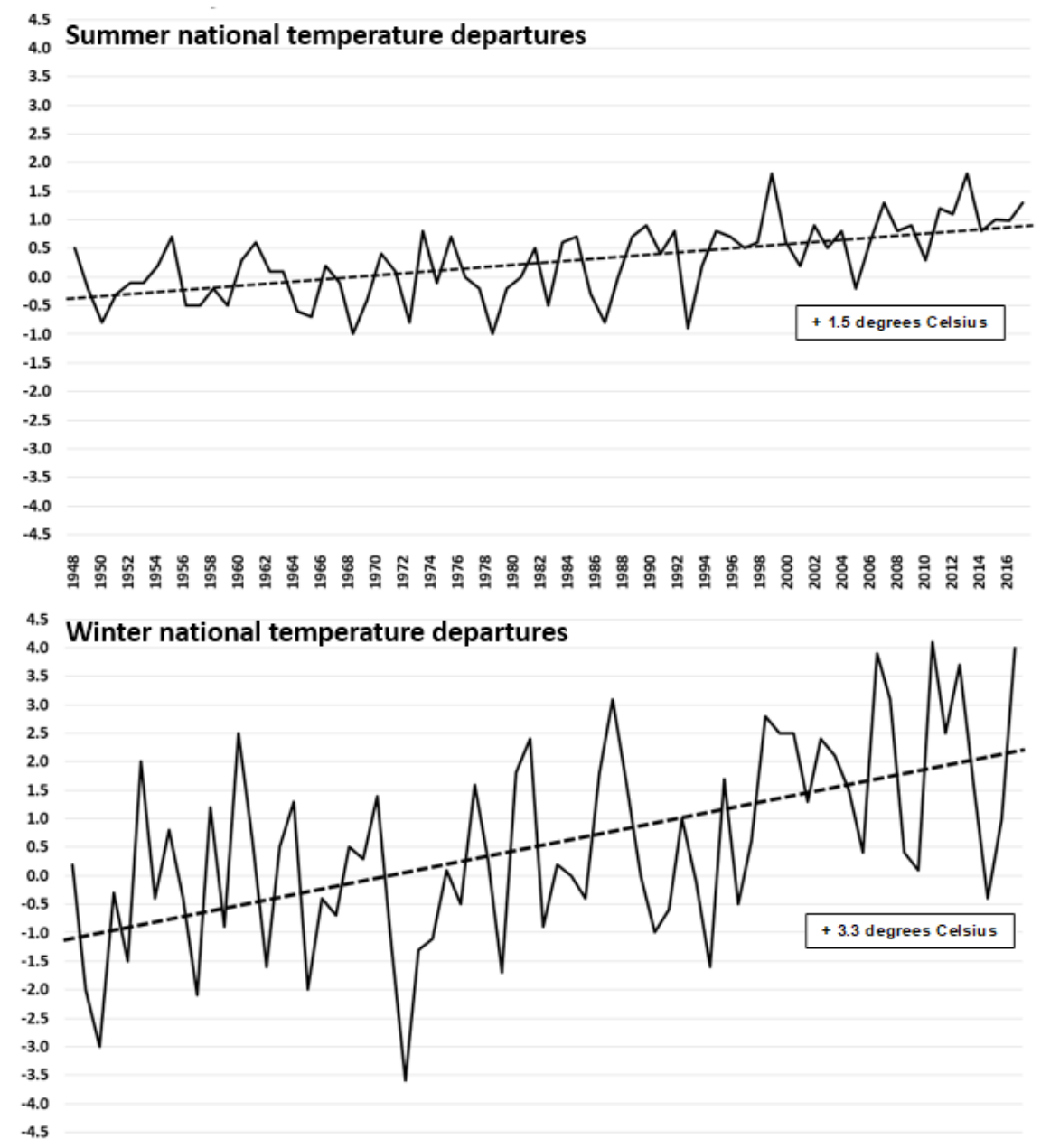

Figure 3. National temperature departures (degrees Celsius) and long-term trend, Canada, 1948-2016.

Source: Environment and Climate Change Canada 2017c. 


\section{Future challenges}

In the early 1970s, Ehrlich and Holdren (1971) formulated the "IPAT equation" with the intention of refuting the argument that population size, in and of itself, was a minor factor explaining environmental change. The IPAT equation was proposed as a starting point for investigating the impact of human populations on the environment. These interrelationships were: I (Impact) $=$ Population $(\mathrm{P}) \times$ Affluence $(\mathrm{A}) \times$ Technology $(\mathrm{T})$, where Impact $(\mathrm{I})$ refers to the amount of a particular kind of environmental degradation (for example, GHG emissions), the size of the population $(\mathrm{P})$, affluence $(\mathrm{A})$ is typically measured in terms of income per capita, and technology $(\mathrm{T})$ is meant to capture the environmentally damaging properties of a particular production technique.

While the model has been criticized as being an oversimplification, its primary utility is to highlight the centrality of demography for discussing environmental problems. For example, the IPCC (2000) has used a slightly revised version (called the Kaya identity) in an attempt to disentangle the importance of demography to increased $\mathrm{CO}_{2}$ emissions at the global level. This model, in various forms, has suggested repeatedly that across nations, regardless of their level of affluence, increased population matters and typically implies a proportional increase in environmental impact.

The impact of affluence (A), on the other hand, is not quite as straightforward because empirical evidence suggests that its effect is neither always proportional nor linear (consider for example, the aforementioned discussion of the Kuznet's environmental curve). While greater affluence is typically associated with a greater carbon footprint, several post-industrial societies have witnessed some decline in GHG emissions due to a shift away from their most energy intensive industries associated with the manufacturing sectors. The role of technology $(T)$ is complex, as both gains in energy efficiency and transition to renewable sources of energy can be important in reducing environmental impact. The success of Canada in using technology ( $\mathrm{T}$ ) to reduce environmental impact should not be overstated, as several European countries have not only increased the energy efficiency of their economies (as is true of Canada), but are also much further along in terms of an energy transition away from fossil fuels toward less $\mathrm{CO}_{2}$-intensive alternatives, including hydroelectricity, nuclear, and, to a lesser extent, geothermal, wind, and solar (Hamilton and Turton 2002; Kerr and Mellon 2012).

\section{Canada's energy transition}

In this context, the insights of Canadian geographer Vaclav Smil are useful. Smil writes that "a world without fossil fuel combustion is highly desirable, and, to be optimistic, our collective determination, commitment and persistence could accelerate its arrival. But getting there will be expensive and will require considerable patience. Coming energy transitions will unfold, as past ones have done, across decades, and not years" (2010: 149).

With this in mind, consider the enormous political, economic and technological challenges involved, as both domestic and international demand for fossil fuels remains high, and a substantial proportion of all Canadian economic activity is tied into investment and further extraction in Canada's resource sector. The future challenge in this context is to move through the energy transition and away from fossil fuels, a necessity that will become more pressing as the impact of global warming becomes more obvious to the Canadian public.

Much of the current economic and political leadership in Canada is highly committed to further expansion of the Canadian energy sector, and Canada has known fossil fuel reserves that are estimated to be third only to Venezuela and Saudi Arabia. For example, since being elected in 2015, the current Liberal government in Ottawa has committed to the expansion of energy exports as 
its modus operandi. This includes support for completion of the Keystone XL pipeline, intended to move bitumen from the oil sands of Alberta to refineries off the Gulf Coast, as well as for Enbridge's Line 3, which will move large quantities of oil through northern Minnesota to Lake Superior, and Kinder-Morgan's Trans-mountain pipeline, meant to meet an expected demand for energy across the Pacific Rim (Carr 2017; McCarthy 2017).

\section{Expanding our knowledge base}

\section{Collaborative research}

In the study of environmental impact, there is a tendency among natural scientists to emphasize the consequences of continuing growth in a finite world (the fixed limits to growth). On the other hand, among social scientists, and economists in particular, there has been a tendency to emphasize the ability of modern economies to create technologies and socioeconomic innovations that have the capacity to modify, control, and sometimes transcend natural environmental limits. Among Canadian demographers, the most commonly acknowledged demographic problem is the issue of population aging, as linked to below-replacement fertility, as well as related challenges that accompany a reliance on immigration to maintain population and labour force growth. Nonetheless, the idea of limiting population growth is seldom debated.

Heavily influenced by the economics literature, there is a tendency to ignore the idea of fixed limits and, if anything, to believe that Canada is perhaps "under-populated" by world standards. This argument has forcefully been made recently in the editorial pages of the Globe and Mail, arguing that "Canada's small population" serves as an obstacle to the country's well-being in the longer term (Saunders 2017a). Yet such argument is not new, and completely consistent with Julian Simon's (1981) widely cited cornucopian views as to the lasting economic benefits associated with continuous population growth. Many social scientists appear to distance themselves from the natural sciences, or from the basic reality that all buman societies are ultimately embedded in nature and the inference that there are obvious natural environmental limits to population growth.

Arguably, there is perhaps an opposite tendency on the part of the natural sciences to ignore or downplay the potential for political, technological, and sociocultural innovation, and to assume that the limits are unyielding and we have little say in the matter (Sabin 2013). This lack of dialogue between the natural and social scientists is a fundamental barrier to promoting a more informed research agenda into how Canada can achieve a sustainable economy, and to incorporate a more comprehensive assessment of the large-scale environmental risks that we currently face.

\section{The energetics of Canadian society}

A useful example of the lack of interdisciplinary dialogue is that relatively few social scientists have been concerned with the social and environmental consequences of energy productionthe energetics of human societies. Yet in light of the very real challenges that we currently face, both globally and nationally, in terms of reducing our reliance on fossil fuels, there is an obvious need for further collaborative research to understand the energy trajectories of different societies. Comparative research with other more developed nations may assist us to better understand the many political, economic, and technological barriers to transitioning to a fossil-free economy. Social scientists can certainly contribute- through research on personal, household, and regional differences in energy consumption, not to mention how international trade and globalization have influenced both the supply and demand for fossil fuels, among other, less $\mathrm{CO}_{2}$-intensive alternatives. 


\section{High-risk choices}

The IPCC has established with near-certainty the association between increased GHG emissions and global warming. On this front, Canada is an important player internationally, particularly given our large fossil fuel reserves. As human environment interactions are complex and include many nonlinear relationships and feedback mechanisms, it is extremely difficult to forecast the pace of global warming, as well as our reaction to it. Yet in light of the extremely high risks associated with a warming planet, the social sciences (and demography) may be very well placed in terms of thinking of high-risk choices in a continuing context of great uncertainty.

Briefly, Figure 4 provides a summary of the IPCC's (2014) most recent set of forecasts (Fifth Assessment Report) on the extent to which average global surface temperatures can expect to rise over the next century. All the forecasts imply a warming climate, yet the range of future outcomes is extremely wide. Four different scenarios are provided (representative concentration pathways, or RCPs), developed by the IPCC to portray four possible climate futures. RCP2.6 assumes that global GHG emissions will peak in the current decade (2010-20), with levels declining substantially thereafter. Emissions in RCP4.5 peak around 2040, then decline, whereas emissions in RCP6.5 peak in 2080, then decline. RCP8.5 is the most pessimistic of all the scenarios in assuming a sustained growth of emissions throughout the 20th century.

Underlying each pathway is a different scenario on future population growth, which in turn is considered fundamental in forecasting emissions. For example, the most pessimistic forecast (RCP8.5) assumes sustained population growth throughout the current century, whereas the most encouraging (RCP2.5) assumes slow growth that stabilizes by mid-century (van Vuuren et al. 2011). In the IPCC's most optimistic forecast (RCP2.6), the underlying assumption on population is not far from the UN's low variant, with global population reaching about 9 billion by mid-century. In the IPCC's most pessimistic forecast (RCP8.5), projected growth is closest to the UN's high variant, with lobal population reaching 10.4 billion by mid-century (van Vuuren et.al. 2011).

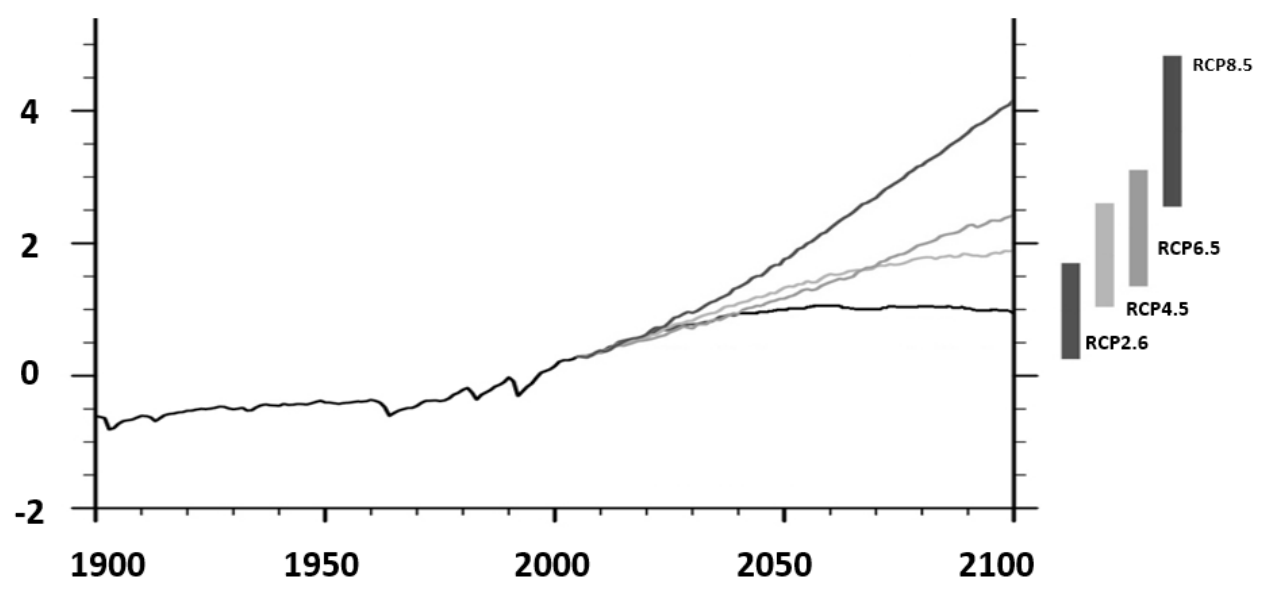

Figure 4. Forecasted average surface temperature change (relative to 1986-2005), degrees Celsius.

Source: IPCC Fifth Assessment Report 2014.

With this wide range on future concentration pathways (and future demographic growth), the only scenario that falls without the target set out in Paris is RCP2.6, with a warming of less than 2 degrees over the longer term historical average. This latter scenario is not realistic, as it implies a very stringent mitigation scenario in terms of reducing GHG emissions (i.e., that the world meet is its Paris commitments) and a rather dramatic slowing in the rate of global population growth 
(with the global fertility rate falling below replacement within a few decades). In addition, with each RCP the IPCC has applied a broad range of climate models which leads to a wide range of forecasts associated with each (this is captured through uncertainty associated with each RCP, as represented by the bars to the left of Figure 4). This uncertainty relates to the complexities of modelling climate beyond the uncertainties in forecasting future population and GHG emission levels. And recall that the pace of warming will be far greater in the northern latitudes; the forecasts implied in Figure 4 will be amplified into far greater warming for Canada's north. The uncertainty in these forecasts remains high, just as do the potential risks associated with some of the worst-case scenarios.

From a standpoint of moving through the energy transition away from fossil fuels, the IPCC forecasts are impacted by projected population growth, with slower growth or even population stability being desirable. The IPCC considers population growth as fundamental to its forecasts on GHG emissions, with greater growth implying higher emissions. This scientific research begins with what is easily verifiable: population size can be considered a fundamental multiplier in estimating environmental impact (this inference is true, regardless of arguments that have been widely circulated as of late on how it is possible to green an economy through demographic growth. The consensus coming out of the IPCC is that major population growth at the global level will be a major obstacle to reducing GHG emissions and obtaining a sustainable future.

\section{Toward population stability}

While forecasting the future is extremely difficult, the social sciences may provide some prudent basis for proposed action and policy on energy use and our continued reliance on fossil fuels. In addition, in light of the enormous difficulties involved in moving away from our dependency on fossil fuels, it would seem well advised that social scientists work more closely with climate scientists in carefully identifying and monitoring the pace of warming in Canada, as to how this impacts specific regions of the country and how we are affected and/or adjust to what is increasingly looking to be inevitable.

In terms of the population component, as global population moves toward stabilization toward the middle of the current century, what will be Canada's future? Given the high level of consumption or affluence (A) that characterizes North America, Canada can arguably play a larger role in climate change through achieving a stable population rather than a growing one. Increasingly, the consensus is that at the global level a smaller population would be better, and the sooner we arrive at population stability the better. This is especially true given rising consumption, which amplifies the impact of demographic growth. A worthwhile debate in this context is the extent to which Canada shares a concern to move toward population stability.

From a standpoint of achieving environmental sustainability, the IPCC has argued that slower population growth or even population stability makes such an achievement more realistic and obtainable. Yet with the globalization of trade, there will inevitably be growth in demand for Canadian resources (and energy resources) regardless of the pace of population growth internal to Canada. Even if Canada were to achieve population stability, there will continue to be major challenges in our efforts to reduce GHG emissions and promote environmental sustainability. While Canada's population could potentially double over the current century (its current growth rate implies a doubling in about 70 years), the far more challenging future remains tied to the basic insight from the UN that we can easily anticipate an additional 2 billion prior to peak population on a global scale. 


\section{References}

Aitken, S., and S. Simard. 2015. Restoring forests. Alternatives Journal 41:30-33.

Cubasch, U., D. Wuebbles, D. Chen, M.C. Facchini, D. Frame, N. Mahowald, and J-G. Winther. 2013. Introduction, in Climate Change 2013: The Physical Science Basis. Contribution of Working Group I to the Fifth Assessment Report of the Intergovernmental Panel on Climate Change. Cambridge (UK) and New York: Cambridge University Press.

Carr, J. 2017. Keynote Address by Minister of Natural Resources. "Canada in Conversation Event," Embassy of Canada, Washington.

Ehrlich, P., and J. Holdren. 1971. Impact of Population Growth. Science 171:3977-95.

Environment Canada (Environment and Climate Change Canada). 2015. The Science of Climate Change. Cat. No. EN4-303/2015E. Ottawa: Government of Canada.

- 2017a. Canadian Environmental Sustainability Indicators: Global greenhouse gas emissions. Ottawa: Government of Canada.

—. 2017b. Progress towards Canada's Greenhouse Gas Emissions Reduction Target. Ottawa: Government of Canada.

- 2017c. Climate Trends and Variations: Summer Bulletin; Winter Bulletin. Ottawa: Government of Canada.

Environment Canada and the US Environmental Protection Agency. 2014. State of the Great Lakes. EPA publication cat no. En161-3/1-2011E-PDF.

Hamilton, C., and H. Turton. 2002. Determinants of emissions growth in OECD countries. Energy Policy 30:63-71.

Hsu, A. 2016. 2016 Environmental Performance Index. New Haven, CT: Yale University.

IEA (International Energy Association). 2017. World Energy Outlook 2017. Paris: Cedex.

IPCC (Intergovernmental Panel on Climate Change). 2000. Intergovernmental Panel on Climate Change: Summary for Policymakers. Cambridge (UK): Cambridge University Press.

- 2014. Fifth Assessment Report, International Panel on Climate Change. Kirtman, B., S.B. Power, J.A. Adedoyin, G.J. Boer, R. Bojariu, I. Camilloni, F.J. Doblas-Reyes, A.M. Fiore, M. Kimoto, G.A. Meehl, M. Prather, A. Sarr, C. Schär, R. Sutton, G.J. van Oldenborgh, G. Vecchi, and H.J. Wang. Cambridge (UK) and New York: Cambridge University Press.

Kerr, D., and H. Mellon, 2012. Energy, population and the environment: Exploring Canada's record on $\mathrm{CO} 2$ emissions and energy use relative to other OECD countries. Population and Environment 34:257-78.

Kuznets, S. 1955. Presidential Address. American Economic Association. New York.

Mandrak, N., and B. Cudmore. 2010. The fall of native fishes and the rise of non-native fishes in the Great Lakes Basin. Aquatic Ecosystem Health and Management 13:255-68

McCarthy, S. 2017. From Standing Rock to Trans Mountain, dissent is in the pipeline. Globe and Mail, 12 November 2017.

NASA. 2017. NASA, NOAA Data Show 2016 Warmest Year on Record Globally. Climate. Earth, Goddard Space Flight Center. National Aeronautics and Space Administration. New York, NY. 
Pizzolato, L., S. Howell, C. Derksen, J. Dawson, and L. Copland. 2013. Changing sea ice conditions and marine transportation activity in Canadian Arctic waters between 1990 and 2012. Climatic Change 123:161-73.

Romero-Lankao, P., J.B. Smith, D.J. Davidson, N.S. Diffenbaugh, P.L. Kinney, P. Kirshen, P. Kovacs, and L. Villers Ruiz. 2014. In North America: Climate Change 2014; Impacts, Adaptation, and Vulnerability. Part B: Regional Aspects. Contribution of Working Group II to the Fifth Assessment Report of the Intergovernmental Panel on Climate Change. Cambridge (UK) and New York: Cambridge University Press, p. 1439-98.

Sabin, P. 2012. The Bet: Paul Ehrlich, Julian Simon and our Gamble over Earth's Future. New Haven, CT: Yale University Press.

Saunders, D. 2017. Maximum Canada: Why 35 Million Canadians Are Not Enough. Toronto: Knopf.

. 2017b. Canada needs a fuller house to thrive, but population growth isn't enough. Globe and Mail, 16 September 2018.

Simon, J. 1981. The Ultimate Resource. Princeton, NJ: Princeton University Press.

Smil, V. 2010. Energy, Myth, and Realities: Bringing Science to the Energy Policy Debate. Washington: AEI American Enterprise Institute.

Thomson, L., M. Zemp, L. Copland, G. Cogley, and M. Ecclestone. 2017. Comparison of geodetic and glaciological mass budgets: White Glacier and Axel Heiberg Island, Canada. Journal of Glaciology 63: 55-66.

UN (United Nations). 2017. World Population Prospects: 2017 Revision. New York: Department of Economic and Social Affairs, United Nations Population Division.

Van Vuuren. D., J. Edmonds, M. Kainuma, K. Riahi, A. Thomson, K. Hibbard, G. Hurtt, T. Kram, V. Krey, J-F. Lamarque, T. Masui, M. Meinshausen, N. Nakicenovi, S. Smith, and S. Rose. 2011. The Representative Concentration Pathways: an Overview. Climatic Change 109.

World Resources Institute. 2016. Climate Data Explorer: Climate Analysis Indicators Tool. Washington: World Resources Institute. 